\title{
CT-guided palladium-103 seed brachytherapy for metastatic adenoid cystic carcinoma: a retrospective study to assess initial safety and effectiveness of percutaneous CT fluoroscopy- guided permanent seed brachytherapy
}

\author{
Stephen W. Doggett, MD, FACR', Kelly W. Elliott, RN MS², Shigeru Chino, MD³, Kevin Burns, MD², Todd Lempert, MD4 \\ 'Mission Hospital, Mission Viejo Radiation Oncology, Mission Viejo, CA, USA, ${ }^{2}$ Eminence Clinical Research, Inc., Colorado Springs, CO, USA, \\ ${ }^{3}$ Mission Hospital, Mission Viejo Thoracic Surgery, Mission Viejo, CA, USA, ${ }^{4}$ Mission Hospital, Mission Viejo Interventional Radiology, Mission \\ Viejo, CA, USA
}

\begin{abstract}
Purpose: Multiple pulmonary metastases present treatment difficulties in available treatment techniques, which are inconvenient or may damage sufficient pulmonary tissue to cause pulmonary crippling. This retrospective study of a single-community practice evaluated responses to computed tomography (CT)-guided ${ }^{103} \mathrm{Pd}$ permanent seed brachytherapy (CTGPSB) in adenoid cystic carcinoma (ACC) synchronous pulmonary metastases. The purpose of the current study was to document that metastatic pulmonary ACC lesions can be controlled with CTGPSB.

Material and methods: Twenty-nine discrete lesions in 14 patients were evaluated with serial CT scans. All were treated with CTGPSB. Lesions were tracked over serial CT scans and volumes measured. Primary endpoint was a reduction in tumor volume on subsequent CT scan. Secondary endpoint was occurrence of CTCAE grades 2-5.

Results: There was a $100 \%$ measured reduction in tumor volume $(n=29)$ at follow-up. Follow-up was a mean of 3.13 years. Baseline tumor volume was a mean of $1.85 \mathrm{ml}$ (range, 0.69-9.15 ml). There were two grade 1 and one grade 2 adverse events, which did not require hospitalization.

Conclusions: CTGPSB for the treatment of multiple ACC pulmonary metastases is effective, with minimal acute complications, as shown in small cohort of subjects of the present study. Further studies evaluating specific dosimetry parameters in this free-hand technique are needed to specify minimal and maximal dose constraints.

J Contemp Brachytherapy 2021; 13, 5: 504-511 DOI: https://doi.org/10.5114/jcb.2021.110346
\end{abstract}

Key words: adenoid cystic carcinoma, pulmonary metastases, palladium-103 implants, brachytherapy.

\section{Purpose}

Adenoid cystic carcinoma (ACC) was first described as cylindroma in 1859 [1]. ACC is an uncommon cancer, usually occurring in salivary gland tissue. Rate of occurrence is approximately 4.5 per 1,000,000 per year. Most common sites of presentation are the minor salivary glands, and submandibular and parotid glands [2]. ACC appears to spread by hematogenous, perineural, and lymphatic routes. However, the hematogenous route predominates in many cases, and metastases to lung, liver, bone, and brain can be observed after long periods of indolence [3]. Approximately half of all patients presenting with ACC will develop metastatic disease or succumb to local recurrence [2]. Majority of metastases will occur in the lungs, with larger primary lesions, local recurrence, and perineural invasion, as the risk factors [4].

Metastatic ACC responds poorly to known chemotherapies, partly due to slow cell kinetics. Published reviews and retrospective studies indicate no accepted standard systemic chemotherapy for patients with ACC tumors $[5,6]$.

Without effective systemic therapies, multiple pulmonary metastases arising from ACC or other histologies are a clinically vexing problem. ACC patients commonly present with multiple lesions in both lungs, therefore risking a pulmonary compromise with conventional interventions for multiple lesions. These patients commonly

Address for correspondence: Stephen W. Doggett, MD, FACR, Mission Hospital, Mission Viejo Radiation Received: 18.03 .2021 Oncology, Mission Viejo, 14642 Newport Ave \# 470, Tustin, CA 92780, USA, phone: +1 714-404-3459, 
present again months or years later with new pulmonary lesions, requiring further intervention.

Subsequent to our initial experience with treatment of recurrent non-small cell lung cancer (NSCLC) with computed tomography (CT)-guided ${ }^{103} \mathrm{Pd}$ permanent seed brachytherapy (CTGPSB) [7], we have had a high-volume community hospital experience with multiple pulmonary metastatic ACC lesions utilizing CTGPSB, and here, present a part of the data showing that multiple pulmonary metastases can be rapidly, safely, and effectively treated.

\section{Material and methods}

A retrospective community hospital study protocol was approved by the institutional review board (IntegReview Ethical Review Board, Austin, TX, USA). This study was performed in accordance with the applicable regulations and the Declaration of Helsinki. Informed consent was waived by the community hospital institutional review board, as this was a retrospective study and all data were derived retrospectively from subjects medical records. The principal investigator's office records were reviewed to identify ACC patients, which had computed tomography (CT) visible pulmonary lesions that could be definitively identified on pre-operative, intra-operative, and 6-month post-operative subsequent CT scans.

Study exclusions were lesions greater than $20 \mathrm{cc}$ or lesions that could not be identified on subsequent scans with some degree of certainty. This led to exclusion of a number of patients with numerous metastasis since definitive identification on subsequent scans was extremely difficult. We observed that the irregular appearance of abscopal effect and post-implant scarring produced positive identification of the index lesion against a dynamically changing background challenging.

Pre-operative and post-operative scans were frequently performed on geographically distant machines, as patients came from other states and other countries. Patients living non-locally were often non-compliant with requests for follow-up status and repeat CT scans, which significantly narrowed the number of patients with evaluable CT data, and therefore inclusion in the study.

Patients residing non-locally, which were nearly all of the ACC patients treated, were requested to have serial CT scans every 6 months and images sent to us for a review. Patients with new lesions seen on subsequent CT scans were requested to return for further brachytherapy. Patients were contacted at four to six months intervals, and asked by email or telephone if they were experiencing pain or shortness of breath. Since this was a retrospective study, data was collected on forms that were developed according to the investigators' standard of care for documentation of medical records of the patients treated with CTGPSB. Our technique for CT-guided permanent seed implants has been previously described in detail [7]. Implant was planned with ${ }^{103} \mathrm{Pd}, 2.0-4.0 \mathrm{U}$ NIST/seed according to the National Institute of Standards and Technology. Planned minimum dose to clinical target volume was predictably selected as $100 \mathrm{~Gy}$, since there were no specific data in the literature found to guide dose parameters for treating gross lung metastasis with lowdose brachytherapy. Dose was selected by a review of the American Brachytherapy Society guidelines for permanent seed prostate brachytherapy [8]. The American Brachytherapy Society boost dose was chosen since we were aware that the free-hand non-template-based nature of our technique would commonly result in 'clumping' of seeds in the center of the tumor. Concern for excessive dose in the surrounding lung caused us to refrain from planning higher doses.

Maximal dose was disregarded due to a desire for achieving high intra-tumoral dose, unless implant was adjacent to the viscus, vessel, or chest wall. During the implant, attempts were made to replicate the plan. Because increasing number of pleural punctures may enhance the risk of bleeding and pneumothorax, we attempted to minimize the punctures by balancing the ideal needle and seed spacing against increasing number of pleural punctures. Typically, lesions of $1-2 \mathrm{~cm}$ in diameter were planned with up to six needles, and implanted with one or two needles.

Bony rib obstruction and impingement of the mass by bronchial and vascular structures were the challenges to satisfactory needle and seed positioning. Multiple occurrences of intra-operative needle repositioning were commonly necessary during implantation near large vessels and the esophagus to avoid puncturing these structures and still achieve target contact. Frequent CT/fluoroscopic imaging was used throughout the procedure to ensure that the needle tips were positioned as planned in relation to the target.

Masses greater than $2 \mathrm{~cm}$ in diameter may require more than one needle puncture and several sub-pleural episodes of repositioning of each needle during seed deposition to ensure adequate lesion dosage. Intermittent CT-fluoroscopic imaging was used during seed deposition to confirm appropriate seed spacing. The patients had post-implant CT for pneumothorax surveillance and post-implant dosimetry planning at the completion of the implant. They were taken to a recovery area and monitored for the next 6 hours, and chest radiograph was taken just before discharge.

Pneumothorax usually required only pleural aspiration of the pneumothorax, while the patient was still on the CT table. Upon CT confirmation of non-recurrence of the pneumothorax, the patients were sent to recovery and discharged home several hours later. Persistent or recurrent pneumothorax is rare, and treated with thoracic vent placement and same day discharge. No termination of seeding procedure was done due to the appearance of pneumothorax or hemorrhage.

Post-implant CT identified lesions were evaluated with MIM Symphony software. The planned dose to gross tumor volume (GTV) was $100 \mathrm{~Gy}$. Post-implant CT images were imported into MIM software and, the images were evaluated and measured by the principal investigator as well as separately verified by two independent reviewers (Eminence Clinical Research, Inc., Colorado Springs, CO USA). All reviewers were trained in the imaging and the use of MIM software by MIM technical experts. Results were reported using descriptive statistics, as no formal analyses were planned. 
Table 1. Demographics and history

\begin{tabular}{lc} 
Variable & $n=14$ \\
\hline Age (years), mean (range) & $52.29(26-78)$ \\
\hline Female, $n(\%)$ & $8(57.14)$ \\
\hline Race, $n(\%)$ & $12(85.72)$ \\
\hline Caucasian (non-Hispanic) & $2(14.28)$ \\
\hline Asian & $0(0.00)$ \\
\hline African-American & \\
\hline Smoker, $n(\%)$ & $0(0.00)$ \\
\hline Current & $1(7.14)$
\end{tabular}

Primary study endpoint was a reduction in tumor volume on follow-up CT scan compared to baseline CT scan for ACC patients treated with CTGPSB using ${ }^{103} \mathrm{Pd}$ seed implants. Secondary endpoint was an occurrence of common terminology criteria adverse events (CTCAE v.5.0) severity grades 2 through 5 during follow-up period [9].

\section{Results}

There were 64 patients who underwent CTGPSB treatment from July 2011 through December 2018 who were considered for this study. Fifty of the 64 patients did not meet qualifying criteria for study inclusion. These were patients for whom follow-up CT scans and/or telephone or email assessment could not be obtained. A total of 14 subjects with 29 lesions, with a range of one to four lesions per subject were enrolled. The retrospective data collection and CT scan comparisons took place from July 2020 through December 2020. The average age was 52 years, with a range of 26 to 78 years, and $57 \%$ of the patients were women. Twelve ( 85.7 percent) of the subjects were
Caucasian, non-Hispanic, and two were Asian (Table 1). All were non-smokers at the time of the treatment; one of the study subjects was a former smoker who stopped smoking in 2018. All lesions included in this study were pulmonary metastases from an ACC primary lesion. The number of seeds per lesion ranged from 5 to 79 per lesion, with a mean of 17.5 seeds per lesion. Lesion implanted with 79 seeds used low activity seeds as the case was delayed for several days, and therefore required placement of more seeds of lower activity. The units of ${ }^{103} \mathrm{Pd}$ per seed ranged from $0.6 \mathrm{mCi}$ to $3.52 \mathrm{mCi}$, with a mean of $2.78 \mathrm{mCi}$. $\mathrm{D}_{90}$ ranged from $64-155 \%$, with average $93 \%$ (Figures 1-3). The United States Nuclear Regulatory Commission instructions to clinicians is to maintain coverage at a $D_{90}$ of $80 \%$ or greater for prostate permanent seed brachytherapy. Our goal was to accomplish this criterion in all lesions, with minimal dose to regions of interest, such as the chest wall, bronchus, and esophagus (Table 2).

Lesion locations, baseline tumor volumes, and tumor volumes at follow-up are reported in Table 2 . The time between implant and last follow-up was a mean of 3.13 years, with a range of 0.83 to 5.92 years. All study subjects, when contacted for follow-up, denied any increased shortness of breath and reported no new pain. There was a $100 \%$ measured reduction in tumor volume at follow-up compared to baseline for the 29 lesions in the 14 study subjects (Table 3 ). The safety results showed that there were three study subjects who developed pneumothorax peri-operatively (Table 4). As per CTCAE criteria, one subject experienced an event of pneumothorax at the time of procedure. This subject was asymptomatic and did not require any treatment; therefore, according to CTCAE criteria, this event was a grade 1 . Two more study subjects developed a delayed pneumothorax, the day after the procedure. One of these subjects suffered from diminished breath sounds, but no shortness of breath. Aspiration was performed, and a follow-up CT

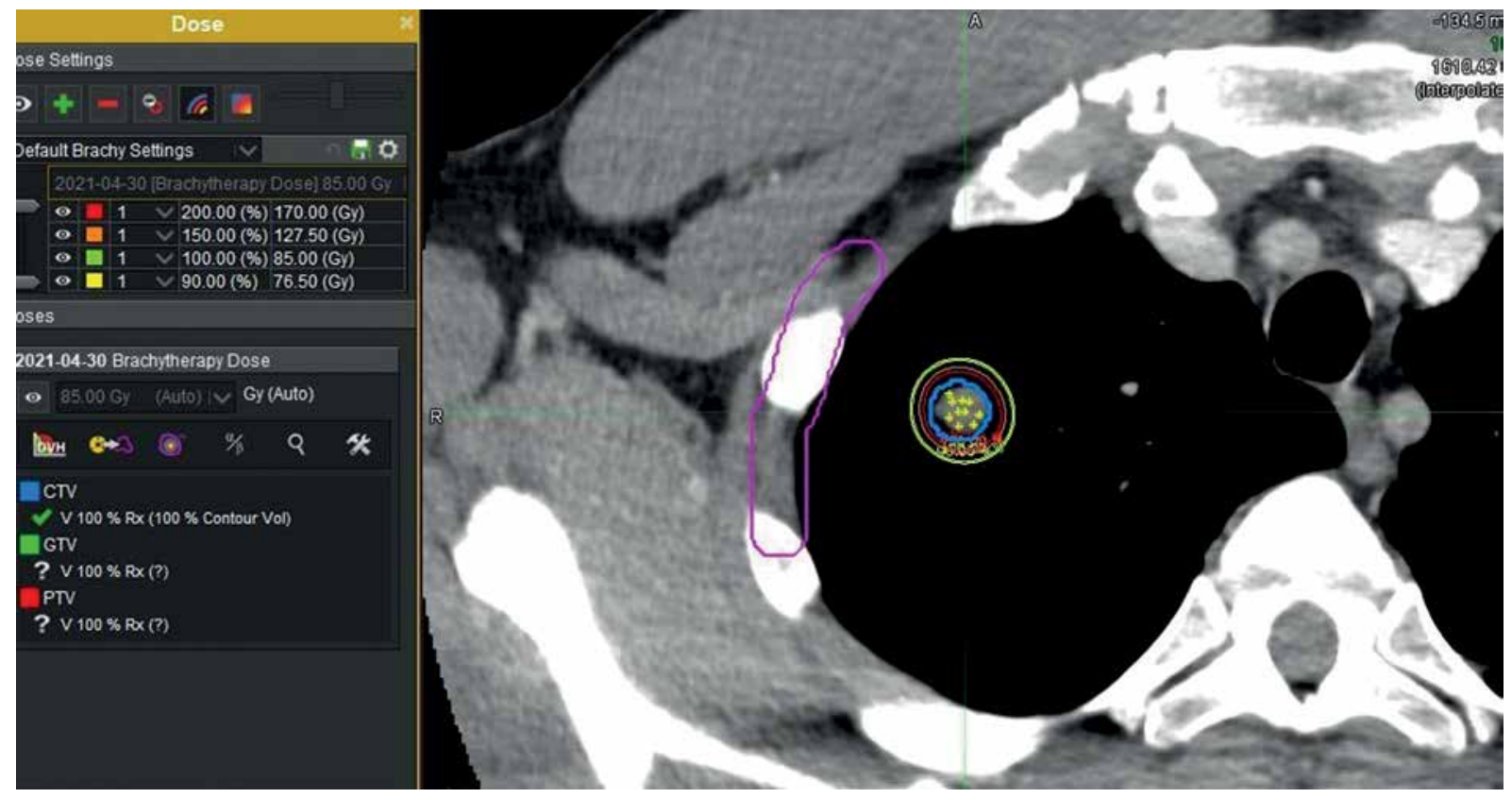

Fig. 1. Right lung lesion post-implant dosimetry 


\begin{tabular}{l|l} 
MIM® 6.9.6 & $\begin{array}{l}\text { Plan description: } \\
\text { Procedure date: }\end{array}$ \\
\end{tabular}

Cumulative DVH (2 of 2 pages)

\begin{tabular}{|c|c|c|c|c|c|c|c|c|c|}
\hline \multicolumn{2}{|c|}{ Dose } & \multicolumn{2}{c|}{ CTV } & \multicolumn{2}{c|}{ PTV } & \multicolumn{2}{c|}{ GTV } & \multicolumn{2}{c|}{ ROI-1 } \\
\hline$\%$ & Gy & $\%$ & $\mathrm{ml}$ & $\%$ & $\mathrm{ml}$ & $\%$ & \multicolumn{2}{c|}{$\%$} & $\mathrm{ml}$ \\
\hline 0 & 0 & 100 & 0.84 & & - & & - & 100 & 6.99 \\
\hline 10 & 10 & 100 & 0.84 & & - & & - & 0 & 0 \\
\hline 20 & 20 & 100 & 0.84 & & - & & - & 0 & 0 \\
\hline 30 & 30 & 100 & 0.84 & & - & & - & 0 & 0 \\
\hline 40 & 40 & 100 & 0.84 & & - & & - & 0 & 0 \\
\hline 50 & 50 & 100 & 0.84 & & - & & - & 0 & 0 \\
\hline 60 & 60 & 100 & 0.84 & & - & & - & 0 & 0 \\
\hline 70 & 70 & 100 & 0.84 & & - & & - & 0 & 0 \\
\hline 80 & 80 & 100 & 0.84 & & - & & - & 0 & 0 \\
\hline 90 & 90 & 100 & 0.84 & & - & & - & 0 & 0 \\
\hline 100 & 100 & 100 & 0.84 & & - & & - & 0 & 0 \\
\hline 110 & 110 & 100 & 0.84 & & - & & - & 0 & 0 \\
\hline 120 & 120 & 100 & 0.84 & & - & & - & 0 & 0 \\
\hline 130 & 130 & 100 & 0.84 & & - & & - & 0 & 0 \\
\hline 140 & 140 & 100 & 0.84 & & - & & - & 0 & 0 \\
\hline 150 & 150 & 100 & 0.84 & & - & & - & 0 & 0 \\
\hline 160 & 160 & 100 & 0.84 & & - & & - & 0 & 0 \\
\hline 170 & 170 & 99.89 & 0.84 & & - & & - & 0 & 0 \\
\hline 180 & 180 & 99.46 & 0.84 & & - & & - & 0 & 0 \\
\hline 190 & 190 & 99.29 & 0.84 & & - & & - & 0 & 0 \\
\hline 200 & 200 & 98.68 & 0.83 & & - & & - & 0 & 0 \\
\hline
\end{tabular}

Fig. 2. DVH at implanted lesion

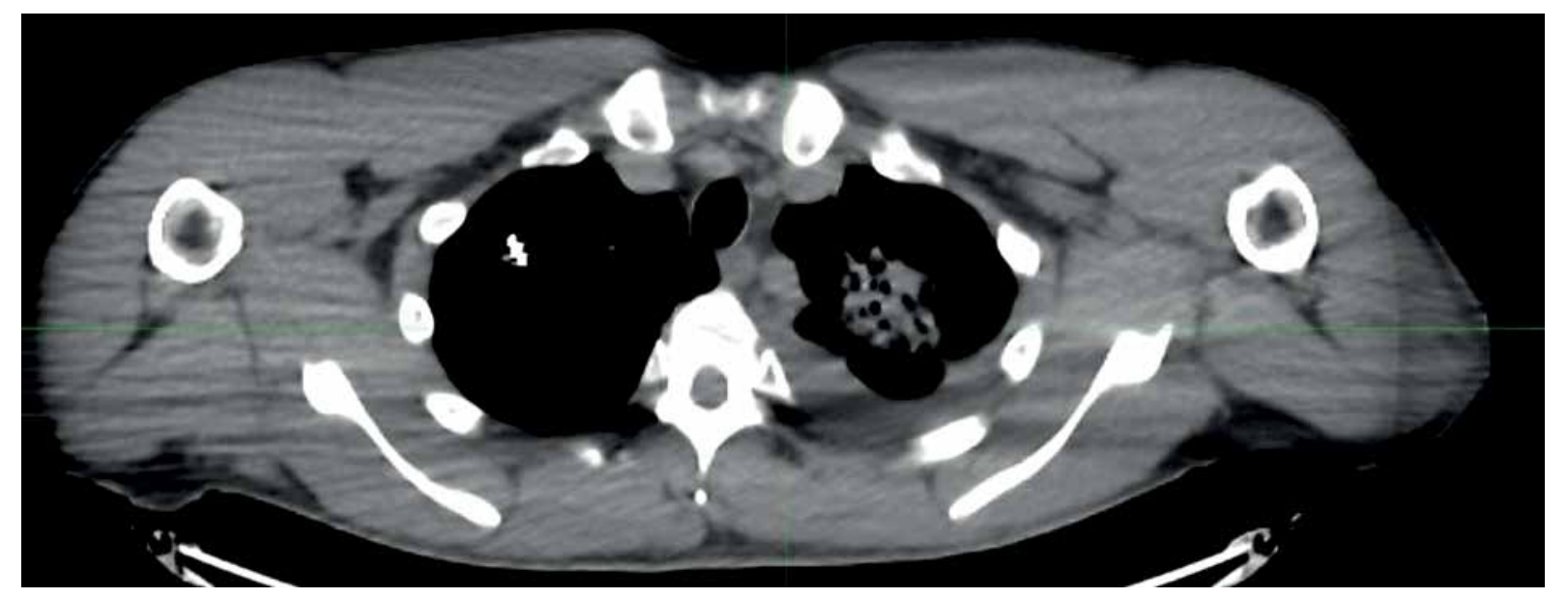

Fig. 3. Right lung lesion at 29 months post-implant

scan was done the following day, showing this adverse event resolved. The third subject was asymptomatic, and no treatment was required. No patient displayed measurable bleeding either by appearance of pulmonary hematoma, pleural effusion, or hemoptysis. The results of this small cohort of the present study presented favorable safety and early positive effectiveness.

\section{Discussion}

Adenoid cystic carcinoma is an uncommon secretory gland malignancy arising from a variety of head and neck
JCB | Seeds:

2021-04-30 Seed strength:

Total seed strength:

Prescription dose:

Isotope:
$2 \mathrm{U}(1.55 \mathrm{mCi})$

$20 \mathrm{U}(15.47 \mathrm{mCi})$

$100 \mathrm{~Gy}$

${ }^{103} \mathrm{Pd}$

MIM-Generated DVHs 
Table 2. Study subject dosimetry

\begin{tabular}{|c|c|c|c|c|c|}
\hline $\begin{array}{l}\text { Subject } \\
\text { number }\end{array}$ & Lesion \# & $\mathrm{D}_{90}(\%)$ & $\mathrm{D}_{90}(\mathrm{~Gy})$ & $\mathrm{V}_{100}(\%)$ & $\mathrm{V}_{150}(\%)$ \\
\hline \multirow[t]{2}{*}{ 01-01 } & 1 & 70 & 92 & 76 & 57 \\
\hline & 2 & 155 & 90 & 100 & 90 \\
\hline \multirow[t]{2}{*}{ 01-02 } & 1 & 100 & 90 & 100 & 96 \\
\hline & 2 & 100 & 90 & 100 & 92 \\
\hline \multirow[t]{2}{*}{ 01-03 } & 1 & 93 & 100 & 89 & 69 \\
\hline & 2 & 86 & 80 & 82 & 61 \\
\hline \multirow[t]{2}{*}{ 01-04 } & 1 & 81 & 84 & 74 & 52 \\
\hline & 2 & 90 & 90 & 100 & 100 \\
\hline 01-05 & 1 & 100 & 215 & 100 & 99 \\
\hline \multirow[t]{2}{*}{ 01-06 } & 1 & 98 & 122 & 96 & 77 \\
\hline & 2 & 64 & 72 & 76 & 57 \\
\hline $01-07^{1}$ & 1 & 115 & -- & 94 & 78 \\
\hline \multirow[t]{2}{*}{ 01-08 } & 1 & 94 & 100 & 90 & 150 \\
\hline & 2 & 91 & 101 & 90 & 80 \\
\hline \multirow[t]{2}{*}{ 01-09 } & 1 & 98 & 124 & 95 & 81 \\
\hline & 2 & 100 & $>200$ & 100 & 150 \\
\hline 01-10 & 1 & 99 & 118 & 97 & 74 \\
\hline \multirow[t]{2}{*}{ 01-11 } & 1 & 100 & $>200$ & 100 & 100 \\
\hline & 2 & 100 & $>200$ & 100 & 100 \\
\hline 01-12 & 1 & 100 & $>200$ & 100 & 150 \\
\hline \multirow[t]{2}{*}{ 01-13 } & 1 & 100 & 197 & 99 & 97 \\
\hline & 2 & 88 & 95 & 84 & 68 \\
\hline \multirow[t]{2}{*}{ 01-14 } & 1 & 90 & 90 & 87 & 74 \\
\hline & 2 & 100 & 145 & 100 & 145 \\
\hline
\end{tabular}

${ }^{1}$ Older version of software did not provide value for $D_{90}$ dose

Metastasectomy is a frequently reported treatment option for patients with various pulmonary metastases; although, patients with insufficient pulmonary reserve may not qualify for surgical intervention [3, 17-19]. Radio-frequency ablation, microwave ablation, and cryotherapy ablation are competing technologies for the treatment of lung neoplasms, with a $0-34 \%$ of local recurrence rate and a pneumothorax rate of $25-39 \%$ [15, 18, 20, 21]. A retrospective study on radio-frequency and cryoablation of ACC lung lesions showed technical success in $91.7 \%$ of lesions, which were limited to a median of two to 3.5 per patient [15].

Data regarding toxicities of treating multiple sites over a span of several years with these modalities are not available in the literature. Tumor debulking is an effective approach in palliative cancer care, as multiple studies demonstrated that reducing tumor volume via chemoradiation or stereotactic body radiation therapy (SBRT) can in many cases improve survival [17, 22, 23]. SBRT is an effective technique for intra-thoracic malignancies with well-elucidated risk factors for chest wall pain and rib fracture [25]. The toxicity profiles for multiple courses of SBRT for intra-thoracic malignancy have not yet been studied in detail. Published work indicates that pneumo- nitis is related to composite doses and timing of subsequent doses of SBRT [26]. Data on toxicities of repeated pulmonary SBRT are sparse and mostly deal with re-irradiation of solitary local recurrences following conventional radiation or SBRT [27]. Retrospective clinical studies of ACC have been published, but data documenting superiority of one treatment modality over another and prognosis beyond 20 years post-treatment are lacking. Initial and repeated surgical treatment of both primary and metastatic ACC lesions has demonstrated longer survival, although judgment of cure 'is almost impossible' due to the indolent course of the disease [28].

Authors of a retrospective surgical series of 109 ACC patients concluded that a lung metastasectomy may have a survival benefit if there is a greater than 36-month gap between primary treatment and metastasectomy. The benefit of removal of some but not all of the metastasis is uncertain [29].

Our initial experience with CTGPSB was with the treatment of NSCLC, which showed positive results in a community hospital case series previously reported [7].

Other investigators have described the capacity of brachytherapy to treat multiple lesions and the ability of ${ }^{125}$ I seed implantation treatment to cause less radiation-induced lung injury compared to SBRT [30,31].

The low energy of ${ }^{103} \mathrm{Pd}(21 \mathrm{keV})$ allows an extremely high deposition of radiation within the tumor over the decay life of the isotope, with a steep dose gradient falloff immediately near the sources. In contrast, the energy of temporary ${ }^{192}$ Ir radiations $(380 \mathrm{keV})$ and external beam and SBRT radiation $(6,000 \mathrm{keV})$, make these energy sources orders of magnitude more penetrating than those of ${ }^{103} \mathrm{Pd}$, and therefore dramatically increase the integral radiation dose to surrounding tissues.

Permanent seed brachytherapy has been demonstrated to have well-known advantages over external beam radiation techniques, which always require ionizing beam transit from the skin to target tissue, thus irradiating normal tissues en route. Permanent seed brachytherapy has favorable dosimetry compared with external beam radiation therapy. For localized prostate cancer, dosimetric comparisons have shown that brachytherapy techniques were clearly superior in terms of normal tissue sparing compared to volumetric-modulated arc therapy, scanned proton therapy, and scanned carbon-ion therapy [32, 33].

The American Brachytherapy Society does not recommend the use of one specific radionuclide for the treatment of prostate cancer [8]. Due to our prior favorable experience utilizing ${ }^{103} \mathrm{Pd}$ curative CTGPSB for NSCLC [7], we decided to continue to use ${ }^{103} \mathrm{Pd}$ in the current study and to use the same planned minimum dose to the CTV of $100 \mathrm{~Gy}$. Other investigators have reported treating non-ACC pulmonary metastasis with a CT-guided free-hand technique. They have reported a $100 \%$ control rate at 6-month follow-up utilizing ${ }^{125}$ I with a prescribed dose of $135 \mathrm{~Gy}$, with a median of 2.6 lesions treated per patient. Iodine- 125 seed implantation treatment of lung metastases $<2.5 \mathrm{~cm}$ was performed using 5-ml syringe as a guide [34].

The planning and treatment of multiple pulmonary malignancies can be a cumbersome, time consuming, and 
Table 3. Lesion locations and tumor volumes at baseline, follow-up, and time point

\begin{tabular}{|c|c|c|c|c|c|c|c|}
\hline $\begin{array}{l}\text { Subject } \\
\text { No. }\end{array}$ & Lesion location & $\begin{array}{c}\text { Needle } \\
\text { approach } \\
\text { used }\end{array}$ & $\begin{array}{c}\text { Baseline } \\
\text { tumor } \\
\text { volume }(\mathrm{ml}) \\
\end{array}$ & $\begin{array}{c}\text { Number } \\
\text { of seeds } \\
\text { implanted } \\
\end{array}$ & $\begin{array}{c}\text { Units of }{ }^{103} \mathrm{Pd} \\
\text { per seed }\end{array}$ & $\begin{array}{c}\text { Follow-up } \\
\text { tumor } \\
\text { volume }(\mathrm{ml}) \\
\end{array}$ & $\begin{array}{l}\text { Follow-up } \\
\text { (months) }\end{array}$ \\
\hline \multirow[t]{3}{*}{01} & R mid lateral pulm & Anterior & 1.88 & 10 & 2.03 & 0 & 44 \\
\hline & R upper mid ant pulm & Anterior & 1.91 & 10 & 1.98 & 0 & 44 \\
\hline & L paraspinal & Posterior & 2.01 & 10 & 1.97 & 0 & 44 \\
\hline 02 & RUL of lung & Posterior & 1.57 & 10 & 2.93 & 0 & 10 \\
\hline \multirow[t]{2}{*}{03} & R lobar fissure & Posterior & 1.10 & 20 & 3.48 & 0 & 39 \\
\hline & R paraspinal & Posterior & 4.55 & 17 & 3.48 & 0 & 39 \\
\hline \multirow[t]{2}{*}{04} & RLL & R lateral & 5.91 & 79 & 1.88 & 0 & 66 \\
\hline & RLL & R lateral & 0.49 & & & & \\
\hline \multirow[t]{2}{*}{05} & R mid pulm & Posterior & 2.53 & 20 & 2.93 & 0 & 17 \\
\hline & R paraspinal pulm & Posterior & 0.96 & 20 & 2.93 & 0 & 17 \\
\hline \multirow[t]{2}{*}{06} & $\mathrm{R}$ paratracheal & L posterior & 0.50 & 8 & 0.61 & 0 & 31 \\
\hline & R paracardiac & $\mathrm{R}$ anterior & 0.38 & 25 & 2.60 & 0 & 31 \\
\hline 07 & R post medial inf level & Posterior & 1.64 & 10 & 2.07 & 0 & 44 \\
\hline \multirow[t]{2}{*}{08} & $\mathrm{R}$ apical lateral & Posterior & 2.58 & 10 & 3.06 & 0 & 21 \\
\hline & L lateral pleural & Posterior & 0.16 & 5 & 3.06 & 0 & 21 \\
\hline \multirow[t]{2}{*}{09} & LLL post medial pulm & Posterior & 3.11 & 10 & 2.94 & 0 & 17 \\
\hline & R post lower chest wall & Posterior & 1.11 & 15 & 2.94 & 0 & 17 \\
\hline \multirow[t]{3}{*}{10} & L lower lateral & Anterior & 1.81 & 10 & 3.67 & 0 & 22 \\
\hline & R paraspinal & Posterior & 2.77 & 20 & 3.52 & 0 & 22 \\
\hline & RLL & Posterior & 1.19 & 10 & 3.52 & 0 & 22 \\
\hline 11 & L post lateral pulm & Posterior & 0.97 & 10 & 3.39 & 0 & 61 \\
\hline \multirow[t]{2}{*}{12} & R post lower lobe & Posterior & 9.15 & 12 & 2.97 & 0 & 37 \\
\hline & RUL ant lung & Anterior & 1.54 & 10 & 2.97 & 0 & 37 \\
\hline \multirow[t]{2}{*}{13} & $\mathrm{~L}$ parotid to Lung & Posterior & 0.24 & 10 & 3.29 & 0 & 25 \\
\hline & L paracardiac pulm & Anterior & 0.69 & 10 & 3.18 & 0 & 18 \\
\hline \multirow[t]{4}{*}{14} & R apex & Postero-lateral & 1.58 & 11 & 2.66 & 0 & 71 \\
\hline & R upper ant lateral & Upper ant & 0.19 & 6 & 2.66 & 0 & 71 \\
\hline & R apex & Posterior & 1.10 & 20 & 3.03 & 0 & 67 \\
\hline & L apex & Posterior & 0.19 & 20 & 3.03 & 0 & 67 \\
\hline
\end{tabular}

Ant - anterior, Mets - metastases, $R$ - right, L - left, RLL - right lower lobe, LLL - left lower lobe, Pulm - pulmonary, RUL - right upper lobe, Post - posterior, Inf-inferior

Table 4. Follow-up period and reduction in tumor volume compared to baseline

\begin{tabular}{lcccc} 
Variable & $\begin{array}{c}\text { Tumor volume }(\mathrm{ml}) \\
\text { at baseline, } \\
\text { mean (range) }\end{array}$ & $\begin{array}{c}\text { Tumor volume }(\mathrm{ml}) \\
\text { at follow-up, } \\
\text { mean (range) }\end{array}$ & $\begin{array}{c}\text { Follow-up period } \\
\text { in months, } \\
\text { mean (range) }\end{array}$ & $\begin{array}{c}\text { Reduction in tumor } \\
\text { volume (\%) }\end{array}$ \\
\hline Tumor volume pre-implant & $1.85(0.69-9.15)$ & & & $100 \%$
\end{tabular}

Table 5. CTCAE adverse events

\begin{tabular}{llccc}
\hline Subject & Adverse event & CTCAE grade & Treatment & Resolved \\
\hline 05 & Pneumothorax & 1 & N.A. & Yes \\
\hline 08 & Pneumothorax & 2 & Aspiration & Yes \\
\hline 12 & Pneumothorax & 1 & N.A. & Yes
\end{tabular}


resource intensive process. Increasing financial pressures on the U.S. institutions demand faster patient throughput when utilizing costly diagnostic and treatment technologies. For radio-frequency ablation, microwave ablation cryotherapy, and SBRT, the number of lesions able to be treated in a single-session can be limited by the time needed to set up treatment technology and imaging devices needed to deliver the therapy. Additionally, concerns regarding normal lung tissue damage by these competing modalities can limit the number and size of lesions.

Advances in CT-fluoroscopic technology have shortened the time required to treat multiple lesions and decreased risk of organs at risk (OARs) damage. A high frame-rate (up to eight images per second) and short delay ( 0.3 seconds) between needle movement and screen visualization of the needle movement, permits accurate needle tip positioning even adjacent to organs at risk. With these advances in imaging technology and increasing team experience, we have been able to implant 14 lesions in one lung in 73 minutes.

We anticipate future studies demonstrating that tumor debulking ability of CTGPSB can also extend survival, which may permit, as yet undiscovered but more effective, systemic treatments to enter clinical treatment space [35].

Retrospective studies, such as the present one, may lack data on various treated patients, thus decreasing the sample size. Data sets were incomplete due to difficulty in obtaining follow-up CT scans from geographically distant and linguistically different sites. In many cases, the differences in hardware and software of distant CT scanners did not permit for identification and analyses of lesions. Lack of contrast material at the time of follow-up scan, differences in CT slice thickness, and unknown patient's body position changes at remote CT facilities, contributed to elimination of many lesions from the analysis. Examination of follow-up CT scans tracking multiple lesions over time is a difficult task. CT-detected lesions' masses on follow-up in this series were listed as recurrent/residual cancers. Lesions determined to be $100 \%$ resolved were identified by the presence of X-ray marker within the seeds without surrounding mass effect. Follow-up CT detection of mass effect surrounding seeds could not be definitely called 'recurrent or residual cancer'. Without repeated biopsy, mass effect could be caused by a recurrent/residual cancer, edema, or immune call infiltration. PET/CT instead of CT alone can improve detection of metastatic spread in ACC [36].

The literature is silent regarding differentiation of recurrence versus benign lesion following brachytherapy. There are few imaging tracers for immune-oncology and are typically utilized in the research departments of large institutions [37]. Resource limitation in this small pilot study did not permit detailed post-operative dosimetry analysis of the treated lesions, nor did permit for histopathologic evaluation of each treated lesion.

\section{Conclusions}

This retrospective pilot study documents the ability of CTGPSB to reduce or eliminate ACC pulmonary lesions using a safe and resource-conserving method. Future tri- als are needed comparing survival of implanted patients and historical survival controls. ${ }^{103} \mathrm{Pd}$ seed implants for the treatment of ACC pulmonary metastases are effective, with minimal complications, in this small cohort of subjects in the present study.

\section{Acknowledgements}

The authors would like to acknowledge the Adenoid Cystic Research Foundation and Theragenics, Inc. (Buford, GA) for their valuable support of this study. We also would like to acknowledge MIM (Cleveland, $\mathrm{OH}$ ) staff, for their assistance to the research staff in the analyses of included CT scans. Lastly, we would like to acknowledge Christopher A. Schultz and Rebecca N. Elliott for CT scan analyses and data management (Eminence Clinical Research, Inc. Colorado Springs, CO, USA) as well as Betty Burns for the research coordination (Aegis Oncology, Tustin, CA, USA).

\section{Disclosure}

The authors report no conflict of interest.

Eminence Clinical Research, Inc. received unrestricted grants from ACC Research Foundation (ACCRF) and Theragenics (Buford, GA, USA) for software license fees, study administration, and data collection and analyses.

\section{References}

1. Billroth T. Beobachtungen fiber Geschwulste der Speicheldriisen. Virchow Arch Path Anat 1859; 17: 357e375.

2. Coca-Pelaz A, Rodrigo JP, Bradley PJ et al. Adenoid cystic carcinoma of the head and neck - an update. Oral Oncology 2015; 51: 652-661.

3. Chappidi S, Chander B, Rajanee SP et al. Adenoid cystic carcinoma of trachea. Eur J Radiol 2004; 52: 107e-109e.

4. Seok J, Lee DY, Kim WS et al. Lung metastasis in adenoid cystic carcinoma of the headand neck. Head Neck 2019; 41: 3976-3983.

5. Laurie SA, Ho AL, Fury MG et al. Systemic therapy in the management of metastatic or locally recurrent adenoid cystic carcinoma of the salivary glands: a systematic review. Lancet Oncol 2011; 12: 815-824.

6. Cerda T, Sun XS, Vignot $S$ et al. A rationale for chemoradiation (vs radiotherapy) in salivary gland cancers: on behalf of the REFCOR (French rare head and neck cancer network). Crit Rev Oncol Hematol 2014; 91: 142-158.

7. Doggett SW, Chino S, Lempert T. A novel approach for salvage treatment of non-small- cell lung cancer: percutaneous $\mathrm{CT}$ fluoroscopy-guided permanent seed brachytherapy for salvage treatment of lung cancer: long-term results of a case series. J Contemp Brachytherapy 2019; 11: 174-179.

8. Davis BJ, Horwitz EM, Lee WR. American Brachytherapy Society consensus guidelines for transrectal ultrasound-guided permanent prostate brachytherapy. Brachytherapy 2012; 11: 6-19.

9. CTCAE v5.0 Common Terminology Criteria for Adverse Events (CTCAE). Version 5.0; National Institutes of Health. Published: November 27, 2017.

10. Bonaparte JP, Hart R, Trites J et al. Incidence of adencocystic carcinoma in Nova Scotia: 30-year population based epidemiologic study. J Otolaryngol Head Neck Surgery 2008;37: 642-648.

11. Bobbio A, Copelli C, Ampollini L et al. Lung metastasis resection of adenoid cystic carcinoma of salivary glands. Eur J Cardiothor Surg 2008; 33: 790-793. 
12. Seok J, Lee DY, Kim WS et al. Lung metastasis in adenoid cystic carcinoma of the headand neck. Head Neck 2019; 41: 3976-3983.

13. Arano N, Yoshiteru M, Futagawa T et al. Lung metastases from cutaneous adenoid cystic carcinoma 23 years after initial treatment. Respir Med Case Rep 2017; 21: 121e-123e.

14. Spiro RH. Distant metastasis in adenoid cystic carcinoma of salivary origin. Am J Surg 1997; 174: 495-498.

15. Vogl TJ, Nour-Eldin A, Albrecht MH et al. Thermal ablation of lung tumors: focus on microwave ablation. Rofo 2017; 189: 828-843.

16. https://www.cancer.net/cancer-types/adenoid-cystic-carcinoma/statistics\#: :text=Each $\%$ 20year $\% 2 \mathrm{C} \% 20$ about $\% 20$ $1 \% 2 \mathrm{C} 200 \% 20$ people,can $\% 20 \mathrm{be} \% 20$ diagnosed $\% 2 \mathrm{C} \% 20$ including\%20 children. Accessed January 17, 2021.

17. Cheung FP, Alam NZ, Wright GM. The past, present, and future of pulmonary metastasectomy: a review article. Ann Thorac Cardiovasc Surg 2019; 25: 129-141.

18. Schreiner S, Dudek W, Lettmaier S et al. Long-term survival after salvage surgery for localfailure after definitive chemoradiation therapy for locally advanced non-small cell lung cancer. Thorac Cardiovasc Surg 2018; 66: 135-141.

19. Tandberg DJ, Tong BC, Ackerson BG et al. Surgery versus stereotactic body radiation therapy for stage I non-small cell lung cancer: A comprehensive review. Cancer 2018; 124: 667-678.

20. Carrafiello G, Mangini M, Fontana F et al. Complications of microwave and radiofrequency lung ablation: personal experience and review of the literature. Radiol Med 2012; 117: 201-213.

21. Liu S, Ren R, Liu M et al. MR imaging-guided percutaneous cryotherapy for lung tumors:initial experience. J Vasc Interv Radiol 2014; 25: 1456-1462.

22. Leppelmann KS, Levesque VM, Bunck AC et al. Outcomes following percutaneous microwave and cryoablation of lung metastases from adenoid cystic carcinoma of the head and neck: a bi-institutional retrospective cohort study. Ann Surg Oncol 2021; 28: 5829-5839.

23. Couñago F, Luna J, Guerrero LL et al. Stereotactic body radiotherapy for oligometastatic disease in non-small cell lung cancer. Front Oncol 2019; 10: 318-339.

24. Wujanto C, Vellayappan B, Siva S et al. Stereotactic body radiotherapy for oligometastatic disease in non-small cell lung cancer. Front Oncol 2019; 9: 1219.

25. Thompson M, Rosenzweig KE. The evolving toxicity profile of SBRT for lung cancer. Transl Lung Cancer Res 2019; 8: 48-57.

26. Muller DA, Dutta SW, Aliotta E. Clinical outcomes and predictors of lung toxicity after multiple courses of lung stereotactic body radiotherapy for early-stage non-small cell lung cancer. Clin Lung Cancer 2021; 22: 234-241.

27. Kennedy WR, Gabani P, Nikitas J. Repeat stereotactic body radiation therapy (SBRT) for salvage of isolated local recurrence after definitive lung SBRT. Radiother Oncol 2020; 142: 230-235.

28. Ishida E, Ogawa T, Rokugo M. Management of adenoid cystic carcinoma of the head and neck: a single-institute study with over 25-year follow-up. Head Face Med 2020; 16: 14.

29. Girelli L, Locati L, Galeone C. Lung metastasectomy in adenoid cystic cancer: Is it worth it? Oral Oncol 2017; 65: 114-118.

30. Li R, Zhang Y, Yuan Y et al. Dosimetric comparison of CT-guided iodine-125 seed stereotactic brachytherapy and stereotactic body radiation therapy in the treatment of NSCLC. PLoS One 2017; 12: e0187390.

31. Li J, Zhang L, Xie Q et al. Comparison of clinical efficacy and complications of $125 \mathrm{I}$ seed brachytherapy and stereotactic body radiation therapy for recurrent pulmonary metastases from colorectal carcinoma. J Contemp Brachytherapy 2018; 10: 360-367.
32. Georg D, Hopfgartner J, Gòra J et al. Dosimetric considerations to determine the optimal technique for localized prostate cancer among external photon, proton, or carbon-ion therapy and high-dose-rate or low-dose-rate brachytherapy. Int J Radiat Oncol Biol Phys 2014; 88: 715-722.

33. Zaorsky NG, Davis BJ, Nguyen PL. Evolution of brachytherapy for prostate cancer. Nat Rev Urol 2017; 14: 415-439.

34. Li J, Zhang L, Sun Z et al. Iodine-125 seed implantation treatment of lung metastases $<2.5 \mathrm{~cm}$ using $5-\mathrm{ml}$ syringe as a guide. J Contemp Brachytherapy 2020; 12: 335-342.

35. Bradley PJ. Adenoid cystic carcinoma evaluation and management: progress with optimism. Curr Opin Otolaryngol Head Neck Surg 2017; 25: 147-153.

36. Ruhlmann V, Poeppel TD, Veit J. Diagnostic accuracy of (18) F-FDG PET/CT and MR imaging in patients with adenoid cystic carcinoma. BMC Cancer 2017; 17: 887.

37. Krekorian M, Fruhwirth GO, Srinivas M. Imaging of T-cells and their responses during anti-cancer immunotherapy. Theranostics 2019; 9: 7924-7947. 